\title{
An exploratory study in conceptualizing user view on digital taste using design thinking
}

\author{
Afdallyna Fathiyah Harun', Juhaida Ismail ${ }^{2}$, Ho Yun Shiang ${ }^{3}$, Nor Laila Md Noor ${ }^{4}$, Hanif Baharin ${ }^{5}$, \\ Saiful Izwan Suliman ${ }^{6}$ \\ ${ }^{1}$ Faculty of Computer and Mathematical Sciences (FSKM), Universiti Teknologi MARA Shah Alam, Malaysia \\ ${ }^{2}$ Faculty of Computer and Mathematical Sciences (FSKM), Universiti Teknologi MARA Pahang Kampus Raub, \\ Malaysia \\ ${ }^{3}$ Kementerian Tenaga, Sains, Teknologi Alam Sekitar dan Perubahan Iklim (MESTECC), Malaysia \\ ${ }^{4}$ MyHCI-UX Malaysia \\ ${ }^{5}$ Institute of Visual Informatics (IVI) Universiti Kebangsaan Malaysia, Malaysia \\ ${ }^{6}$ Faculty of Electrical Engineering, Universiti Teknologi MARA Shah Alam, Malaysia
}

\begin{tabular}{l} 
Article Info \\
\hline Article history: \\
Received Apr 28, 2019 \\
Revised Jun 30, 2019 \\
Accepted Jul 12, 2019 \\
\hline
\end{tabular}

\section{Keywords:}

Design thinking

Digital taste

Human-computer interaction

Taste experience

User experience

\begin{abstract}
Experiencing food involves the accumulation of multiple senses, experienced through visuals, auditory and palatability. There has been significant growth in digitizing taste using electrical and thermal components to stimulate taste sensations where users need to lick devices or place a metal peripheral on their tongue. Such unnatural interaction appears undesirable motivating us to explore if taste experience could be stimulated by just viewing images of food on a digital platform such as a website or mobile application. This places considerable emphasis on understanding user association to food images and the perceived food taste. Inability to understand their needs before-hand may result into a technological artefact with poor potentiality to trigger taste experience and not excite them to try the food they view on a digital platform. Using Design Thinking as an approach, we were able to identify user perceptions and expectations from digital food images as well as their desires on how such images could trigger their interest to try the food. This paper presents the findings from the Design Thinking excursions, the resulting Digital Food-Taste Experience Design Model and strategy for the next phase of research.
\end{abstract}

Copyright $@ 2020$ Institute of Advanced Engineering and Science. All rights reserved.

\section{Corresponding Author:}

Afdallyna Fathiyah Harun,

Faculty of Computer and Mathematical Sciences (FSKM),

University Technologi MARA Shah Alam,

40450 Selangor, Malaysia.

Email: afdallyna@tmsk.uitm.edu.my

\section{INTRODUCTION}

A digital platform such as a website or a mobile application can serve as window between a tourist and location of interest. It can deliver information as they seek travel experience before departure or when on-site, helping them to get around and finding places to eat. A nation's cuisine can be central to a user's experience and can be a catalyst for tourism products [1]-[4] which is often promoted through close-up digital images of food [5]-[10]. However, the dominant objective in using such method is generally to promote food as the nation's identity rather than opening an avenue of digital taste experience. Tourism is no longer a reserved concept to visiting a place of interest but it is an experience of mind and emotion [11] hence when it comes to food, some degree of experience [12] should be provided so users could anticipate the taste and how delicious the food would be. 
Taste experience is an accumulation of visual, auditory and palatability experience. Existing research proposes artificial tongue as a taste experience mediator [13]-[15] which can be unsightly, intrusive, impractical, and rather ungraceful to interact with. An opportunity presents itself in the Web where digital images are abundant. Digital image can be a powerful trigger for perception process [16]-[19] as it embodies sense-making and communication where eyes discern, and brain understands. As user perception is part of an experience mechanism, studies pertaining to user's food taste perception based on a digital image of food is relatively scarce, revealing a gap on user's point of view as an important component to digital taste experience. Therefore, it is crucial to explore if digital images of food can facilitate taste experience when users are only provided with visual stimulus over the Web platform.

It is in the above context that this study sets out to explore the use of digital food image over a digital platform such as website/mobile application to stimulate taste from user's perspective. To understand how users would interact with digital images over the digital platform, this study has adopted the Design Thinking method which allows an iterative manner to understand user's challenges and preference through a series of excursions, interactions with users and prototyping [20]-[22]. This serves as an attempt to underline strategies and solutions to the problem context. The findings of this study are expected to provide useful insights on how digital platforms could be used as an enabler to provide virtual food experience with a focal on Malaysian local dish. The digital platform referred to throughout this paper refers to website and mobile application as we believe these are the two platforms typically used by tourists to seek information on food over the Internet at places they are visiting. Thus, to help with content readability, we have simplified the reference of website and mobile application as 'digital platform'.

\section{RESEARCH METHOD}

\subsection{Study Approach}

Our study adopted the Design Thinking (DT) approach. Its core value is on human-centred design approach [23] that ensures user needs takes centre stage in any technology design decisions. This methodology is increasingly being adopted in technological artefact development in order to create a usercentred technology solution particularly those involving Human-Computer Interaction. Design Thinking process model comes in many variants but generally comprises five phases, summarized in Figure 1 . The phases are not obliged to occur in sequence but can occur in parallel and reiterated.

The strength of Design Thinking is that it centralizes on prototyping and testing. It also encourages phase reiterations where depending on the progress of ideation (i.e. feasibility of idea, novelty of idea), we may repeat the previous phases of the methodology for idea revision or push forward for idea prototyping by constantly involving user in the technology design decision [23][24]. Other System Development Lifecycle models on the other hand leaves most of the decision-making process to the discretion of the developer where more often than not, users are left out in critical feature decisions. Design Thinking seeks a holistic and empathic understanding of users and context of use. This is done by having designers/developers go out into the field and interact with users which we call excursions.

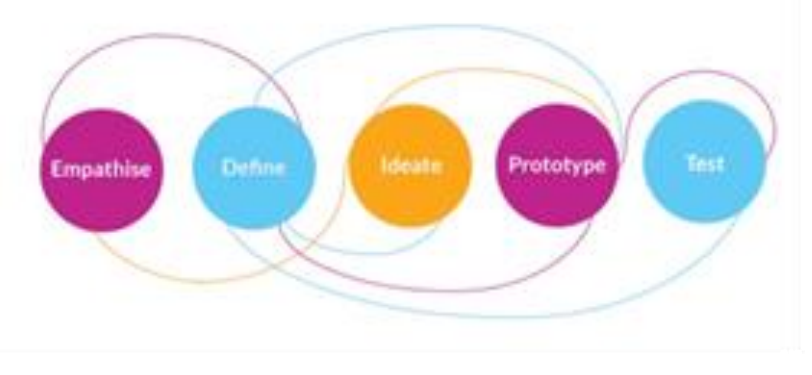

Figure 1. HPI-D Design Thinking Model (Source:[25])

\subsection{User Selection}

Our research is mainly motivated in understanding design attributes required for a digital platform design in stimulating digital taste experience among tourists. To achieve this, our participants should be keen to discuss Malaysian food even if the tourists have little exposure to Malaysian food. We feel that the 
minimal exposure could provide a more genuine thought on how digital food image could affect their taste perception.

We opine that locations such as train stations and shopping complexes would be a magnet point for tourists where they may be in transit or unwinding from their tourism activity giving us opportunities to talk to them casually. This allowed us to employ random sampling which we aimed to gather as many user feedback possible within two hours of each excursion activity.

Food is assumed as a universal topic that could easily draw people together. We held to this assumption as we randomly approached tourists to get their feedback. We filtered users into tourist group with the following demographic questions:

a. Their country of origin; to distinguish between Malaysian and non-Malaysian participants, and

b. The ability to converse in English; this helps to ensure our participants understood the questions being asked and could provide feedback accordingly.

\subsection{Study Setup}

The underlying setting of Design Thinking method is the pragmatic nature of its iteration [23]. Design decisions are made based on the findings of each Design Thinking phase. This could call for either phase continuity or reiteration of previous phases. To achieve the former, the Design Thinking method warrants a check on data sufficiency for in-depth analysis as to allow researchers to derive into a conclusion before moving forward. Each of the phases encourages the use of tools for researchers to generate and present idea as well as to capture user feedback. For this study, we have adopted the Design Thinking model from Hasso Plattner Institute School of Design Thinking, as shown in Figure 1.

It is central to acknowledge the condition of our study as it would help understand the nature of the results obtained. The study was conducted as part of Genovasi Malaysia Design Thinking Innovation Ambassador (DTIA) programme that took place from 25th to 29th July 2018. Briefly, DTIA trains participants on Design Thinking concept through a hands-on approach in a fast-paced manner (i.e. daily session of 8 hours). The training session took place for two and half days while the remaining days of the week was reserved for participants to apply the skills gained from the training session in a project of their own. It was during the latter training period did we conduct the study where we had two and half days to complete our data collection and design concept where several hours of the day dedicated to specific Design Thinking phases as shown in Figure 1. A studio setup was used where Genovasi has provided whiteboards, markers, Sharpie pens, post-it notes and art-craft materials (i.e. unused cardboard, magazine cut-outs). The post-it notes was the handiest tool as it was used to write our thoughts and can easily stick and unstick on the whiteboard as we get our ideas and discussions organised in each of the phase [25].

\subsection{Design Thinking Phases \\ 2.4.1 Empathise}

The goal of this phase is to understand how users experience specific phenomenon. As afore mentioned, we wanted to understand the design attributes for a digital platform that is able to stimulate digital taste experience. To do this, we first needed to explore user's taste perception based on digital images of food. We prepared probes comprising digital images of Malaysian local food as shown in Figure 2. The food was chosen based on internet review of cuisines regarded as Malaysian identity as well as food considered spicy. For clarification, food shown in Palette A of Figure 2 (left to right, top to bottom) are Assam Laksa (spicy-sourly fish-based rice noodle broth), Ikan Bakar (Grilled Fish), Penang Nasi Kandar (steamed rice served with curry varieties and choice of side dishes), Otak-otak (grilled fish cake), Sambal Hitam (black hot relish with anchovies, birds eye chillies, and shallots) and Laksa Johor (spaghetti noodles served with fish and prawn broth).

Food shown in Palette B of Figure 2 (left to right, top to bottom) are Wat Tan Hor (flat noodles in egg gravy, Nasi Ulam (steamed rice dish mixed with shredded herbs, and grated pan-roasted coconut), Chicken Rice, Roti Canai (flatbread served with curry), Nasi Lemak (fragrant rice cooked in coconut-milk and screwpine leaf, served with anchovies, peanuts, boiled egg, cucumber and red chili relish) and Laksam (flat noodles served with fish coconut-milk broth, shrimp paste, cucumber julienne and sliced bean sprouts).

A series of questions such as "Rank the food from spiciest to the least spicy", and "Rank the food from tastiest to less tasty", were asked to the users using the probes seen in Figure 2. Taking advantage of the pragmatic nature of Design Thinking method, the questions did not remain constant from one user to another and this was so as we uncover the practicality of the questions based on user responses. Nevertheless, the questions asked consolidated on understanding their needs, desires and difficulties in the problem context. 


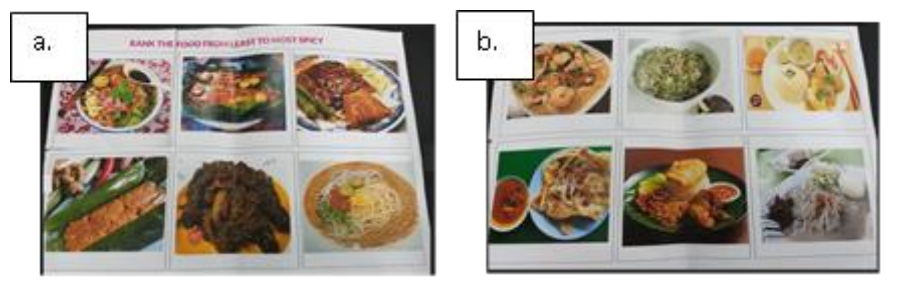

Figure 2. Empathise Phase Probes

This phase excursion took place at Kuala Lumpur Sentral Railway Station and Nu Sentral Shopping Mall in Kuala Lumpur, Malaysia. The former was chosen as it is Malaysia's largest transit hub connecting both local and international travellers from Kuala Lumpur International Airport to other local rail networks allowing tourists to travel to various states in Malaysia and locally in Klang Valley. The latter was chosen as NU Sentral is adjacent to KL Sentral where tourists are often found to unwind here as they wait in transit for their coming trains. We completed the empathise phase within two hours.

\subsubsection{Define, Ideate, Prototype}

In the Define phase, we analysed user responses gathered from the Empathise phase to help us uncover important patterns concerning user experience on Malaysian food, taste perceptions based on the image probe as well as their expectations on food explorations in Malaysia. This is part of a linear unpacking process which highlights users' Point of Views (POV) which captures user requirements in the design of a digital platform stimulating digital taste experience via digital images of Malaysian food. We completed the Define phase within 1 hour.

Brainstorming plays a critical role in the Ideate phase [26]-[29] as we propose as many solutions as possible to address user's POV's. An idea is then selected for prototyping based on novelty and practicality of application. This phase was also done within one hour.

Using mainly recyclable materials, we produced a throwaway prototype in the Prototype phase to illustrate the look and feel of our proposed digital platform solution. As sophistication was not expected, the prototype development was neither expected to fit into a specific dimension measurement nor would it function. Nevertheless, it has element of interactivity and sufficient content so users could interact with the prototype to a certain degree allowing them to potentially see how the digital platform solution proposal might work. This phase was completed within 90 minutes.

\subsubsection{Test}

The testing session consisted of two activities, (i) to assess our proposed digital platform design, and (ii) to tabulate testing insight into Feedback Grid. To assess the feasibility of our solution, the prototype was presented to six users. The session began with explaining the purpose of the test, presenting the prototype to the users demonstrating how the proposed technological solution would work as well as obtaining their feedback on elements in the design that could be improved.

We chose MidValley Shopping Mall as well as the MidValley Komuter Train Station for the activity excursion. Both locations are in the central city of Kuala Lumpur. The former was chosen as it is one of Malaysia's largest shopping mall frequented by tourist. The latter was chosen as it is just next to the shopping mall and used by tourists to return to nearby hotels, visit MidValley as well as head towards Kuala Lumpur city centre. We completed this testing activity within two hours.

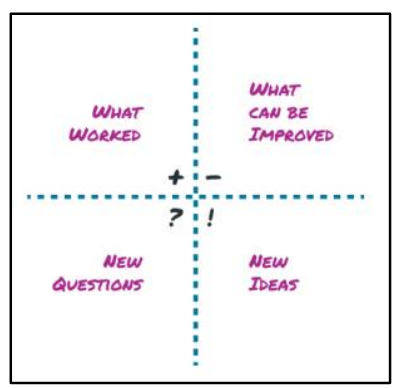

Figure 3. Feedback Grid (Source: [30]) 
This is followed with producing a Feedback Grid as shown in Figure 3 where user feedback on the prototype design is categorized accordingly. This activity is crucial as it helps conclude the next course of action-to move forward with prototype refinement or reiterate with previous phases.

\section{RESULTS AND ANALYSIS}

As we wish to illustrate the pragmatism of Design Thinking methodology, the results shall be presented in terms of the Design Thinking process flow. It is expected that such presentation would present the justifications and implications of decisions made.

\subsection{Empathise and Define}

Our excursion for the Empathise phase led to four users - one local tourist (who is a non-Kuala Lumpur native) and three international tourists. All international tourists were first timers travelling in Malaysia and were found to travel with partners. They came from India, Germany and Italy.

Some of the users did not use Google website or any other Internet browser to browse for food information prior to their travels to Malaysia as they wanted to control the element of surprise, curiosity and exploration. Nevertheless, when ordering food, most of them would look at pictures of the food on the menu, browse information from the Internet as well as get waiter's recommendation.

The tourists have tried Nasi Lemak and Roti Canai upon their arrival in Malaysia. One user was ecstatic sharing his experience in eating Nasi Lemak. He was surprised on how a simple dish was able to "blow his taste bud" and he attributed it to the taste of the rice and the hot relish. He further added that he expected his next Malaysian dish should meet the standard set by Nasi Lemak. This sentiment is not shared by the local user interviewed as he felt Nasi Lemak is a common food and can easily be found by the street, Mamak stall and many local restaurants. He suggested that we should promote state-dish to the tourists as Malaysia has so much more to offer (e.g. Sate in Selangor state, Char Kuey Teow in Penang state, Pais Tempoyak in Pahang state)

Users felt that food should be presented in a sanitary and clean manner. A sense of food similarity to their local cuisine is also useful for them as it helps them predict the taste and texture of the food. However, this requirement is not critical for them. The local user did however point out that some pictures found on the Web does not correctly reflect the dish appearance - for example the dish Pais Tempoyak should be yellowish with shredded leaves and appearance of oil, but pictures on the web appears orangey and lack of oil.

In response to the image probe, the top three foods perceived as spicy are (in order of appearance) Nasi Kandar, Sambal Hitam and Ikan Bakar. The tourists attributed the appearance of red sauce and sliced chilis as being spicy which is a common reference to red chilis being hot. The user from India further added that the colour of the sauce on Nasi Kandar is akin to Massala which is spicy. Surprisingly, Sambal Hitam was also attributed as being spicy even though the colour of the relish is black. This is because the users have a preconception that black sauce in Asian cooking indicate that it is made of chili and is oily. The local user on the other hand opine that none of the food looked spicy. He suggested that the spiciness level depends on the colour of the gravy - green (least spicy), yellow (medium spicy) and red (spiciest). However, this cannot be generalized to all Malaysian cooking as there are green gravy dish which can be spicier than yellow and red gravies. This shows that perception of taste may differ from locals to the foreigners. Also, having experience of eating the food would give a more accurate perception of the taste.

In terms of tastiest food, most of the users have chosen Wat Tan Hor. They felt the dish presentation highlights the ingredients and it looks vibrant and appetizing. Additionally, it highlights the presence of prawns which was a favourite ingredient for most of the users. On the other hand, Nasi Ayam and Laksam was labelled as least tasty. One of the user noted that both dishes looked 'mild' and would not 'excite my taste palate'. This may imply that dish with more vibrant colours and ingredients can infer to user that it is tasty. Additionally, presence of favourite ingredient on the food image can give a preconception that the dish would be tasty. It must be noted that taste experience stems from visual palatability where the sight of food in terms of colour, glossiness and shape would influence how tasty the food would be [31][32].

\subsection{Ideate}

Based on the findings from the Define phase, we have ideated several solutions we feel are probable for the research problem. The ideas were (i) Food Advisor Mobile Application - to advise a list of Malaysian state-dish and national dish, (ii) TasteTaurus Mobile Application - recommending a list of food based on specific taste such as spicy, sweet, salty, sour, umami (iii) e-Taste Mobile Application - a mobile application that provides ingredients list, food video and tasting expressions of specific Malaysian local dish, and (iv) Food Game Mobile Application - recommending Malaysian food based on ingredients selection. 


\subsection{Prototyping and Testing}

We motion that food images can easily be retrieved from websites and social media. Moreover, as the subject matter involves digital food experience by tourists and potential tourists, we feel that the use of a mobile application could easily bring digital food images to life by allowing users to interact with associated content in a few clicks. Therefore, we chose to move forward with the e-Taste Mobile Application idea. Using cardboards, magazine cut-outs, post-it notes and coloured pens, we produced a throwaway prototype as shown in Figure 4 that mimics how the main page of the apps would look like as well as some of the features it offers. Assam Laksa Prop and Video Still Images for e-Taste Mobile Application Video Prototype as shown in Figure 5.

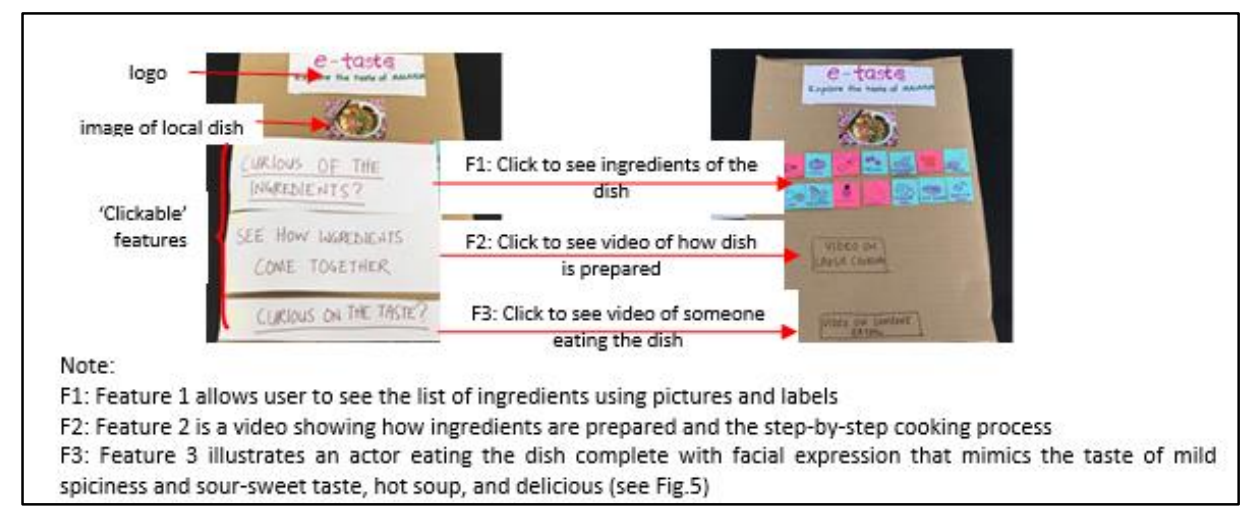

Figure 4. Throwaway Prototype of e-Taste Mobile Application

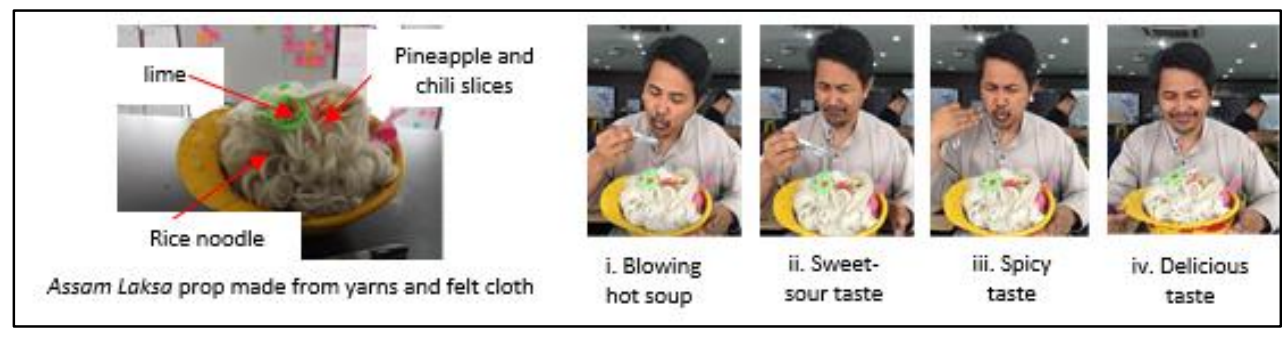

Figure 5. Assam Laksa Prop and Video Still Images for e-Taste Mobile Application Video Prototype

Within the two-hour timeframe, we managed to get feedback from six users where all of them happened to be husband and wife couple. We categorized them as couples C1, C2 and C3 where their user profile is summarized in Table 1. The key findings discussed in this section is based on the Feedback Grid of which the points were elicited from the user feedback as shown in Figure 3.

To demonstrate the functionality of the throwaway prototype, users were first shown the image of Malaysian food (a picture of Assam Laksa) and were inquired if they knew the name of the local dish. All users did not know of the name except for couples C3. The wife made an educated guess based on the garnishing of the dish and the cutleries present in the image. It is also important to note at this point that $\mathrm{C} 1$ and C3 have experienced tasting Assam Laksa before but unaware of the name.

Table 1. User Profile from Prototyping Phase

\begin{tabular}{ccc}
\hline Couples & Country of Origin & Frequency of Malaysia Visit \\
\hline C1 & Iran & Have been staying in Malaysia for 8 years \\
C2 & Japan & First time in Malaysia. Have been staying for 3 days and plans for 10-days stay \\
C3 & Australia & Annual return visit to Malaysia for the past 20 years \\
\hline
\end{tabular}

Couples $\mathrm{C} 1$ felt repulsed when told it the image of the food was Assam Laksa due to their bad experience with it before - they felt that noodle and fish should not be eaten together. This is rooted in their 
Persian food culture where fish is either eaten by itself or accompanied with rice and nothing else. Couples $\mathrm{C} 2$ on the other hand guessed it as Ramen due to the rice noodles they saw in the image as well as the cutleries used. Couples C3 interestingly pointed out that the presentation looks tasty, but such presentation is not found in the street market. It was also highlighted that there is no standardization of presentation among street food sellers as different stalls present their Assam Laksa differently.

As can be seen in Figure 4, Feature F1 would generate a list of ingredients for the Assam Laksa dish. All couples felt that Feature F1 can give an initial indication of spicy and sour-sweet taste due to the pictures of chili and bird-eye chili for the former and lemongrass and lime for the latter. Couples C3 further stated that providing list of ingredients for a specific Malaysian food is very educational. Additionally, couples C3 appreciated the complexity of the ingredients used in Assam Laksa. It was also noted that upon looking at the ingredients picture, couples $\mathrm{C} 1$ and couples $\mathrm{C} 3$ found some of the ingredients were not to their liking and can opt-out from eating it if provided with such information when deciding on food to eat. Users were also surprised to learn that some of the ingredients in Assam Laksa are optional garnishing. They had assumed that any food served to them in restaurants cannot be personalised. Following this, they suggested that the list of ingredients is categorized into garnishing and main ingredients, so they could be further educated on how they could enjoy the food by personalizing the optional garnishing.

Feature F2 in the throwaway prototype suggests the use of video to visualize how the Assam Laksa dish is prepared. For the prototype demonstration, we have played a YouTube video of Assam Laksa ingredients being prepared and cooked. All couples found Feature F2 useful, however couples C1 and C2 did not watch until the end. This may imply that a shorter video would be more appealing. Couples $\mathrm{C} 3$ on the other hand showed appreciation to the cooking process upon realization that making Assam Laksa is not a straightforward process. Moreover, the video made the husband excited, hungry and would like to have Assam Laksa for lunch later that day. This is supported in the observation by [31] where digital presentation of food can elicit emotional responses such as appetite, hunger and mood.

Feature F3 for the throwaway prototype shows a video where an actor pretended to savour Assam Laksa as shown in Figure 5. The actor mimicked various taste expression to highlight different taste dimension of Assam Laksa such as spiciness, sour-sweet taste, hot and delicious as shwon in Figure 5. We received mixed response from the users. Couples $\mathrm{C} 1$ could relate to the sour-sweet expression as it reminded them of their experience. They disagreed with the 'delicious' facial expression as they felt Assam Laksa is not a delectable dish. This indicates that taste perception can be attributed to previous experience. Couples $\mathrm{C} 2$ thoroughly enjoyed the video and found it very exciting. They felt the video would help them have a preconceived idea of the dish taste and is keen to try it out. Nevertheless, they further added that it would be more relatable if a Japanese person were to make the facial expression instead of Malaysian. Couples C3 on the other hand found it upsetting. They felt that some of expressions made in the video did not do justice to the Assam Laksa dish. The wife opines that having Assam Laksa for the first time may result into some of the expression shown, however, as the taste settles, the dish can be very mouth-watering. Upon inspecting the video, we noticed that the actor cringed too much when mimicking sour-sweet taste which may have upset them. The husband further added that such video could be a turn-off to Westerners as it takes a way the taste revelation through actual tasting. Henceforth, Feature F3 should be an optional feature of which users who wish to be surprised can opt not to click the application link.

\subsection{Thematic Analysis on User Feedback Data}

User feedback from all phases of Design Thinking methodology were analysed thematically to identify patterns of user feedback which underlines user requirements in the design of a digital platform to stimulate digital taste experience. The user feedback was coded and classified into Main Design Themes and Design Attributes. This is summarized in Table 2.

Observing the Design Attributes for each of the Main Design Themes, other sets of pattern becomes evident; (i) Suggestive Design Elements - design themes that helps initiate food exploration, (ii) Persuasive Elements - design themes that persuade users in making perception on food taste, (iii) Digital Taste Perception Elements - user's concluded taste perception based on digital image presentation and (iv) Digital Taste Experience Elements - desired food experience sought by user. A refined view of Table 2 based on the set of observed patterns can be seen in Table 3.

Figure 6 illustrates a model presentation depicting how all system design elements come together. It can be used as a reference point for system designers in considering how elements should be applied in a system design to stimulate digital taste experience via digital platform. In actuality, the model underlines user requirements for such system validating the model design as we had obtained user feedback through a scientific approach. 
Table 2. Main Design Themes and Design Attributes from User Feedback for System Design Consideration

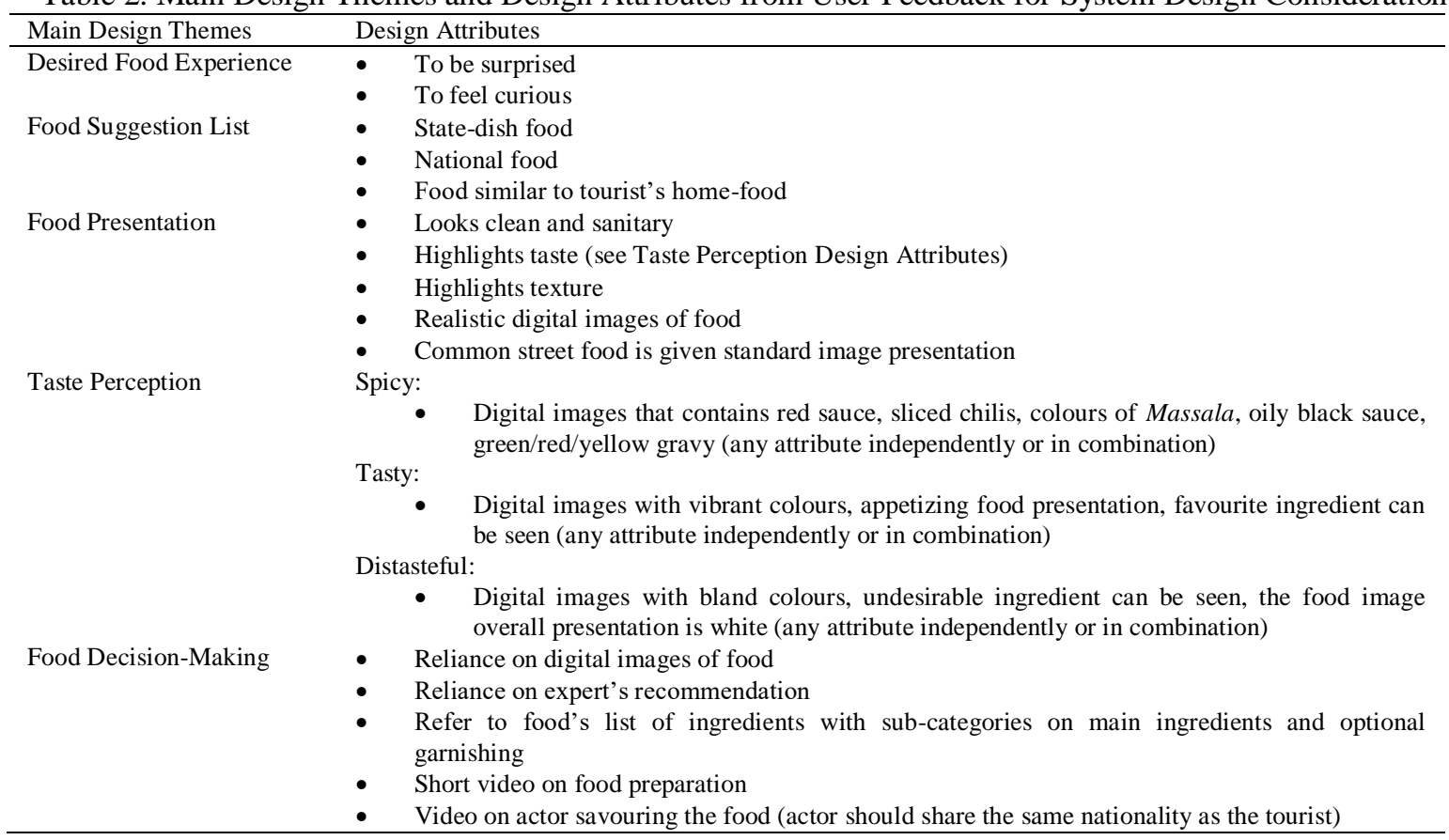

Table 3. System Design Elements based on Main Design Themes

\begin{tabular}{cc}
\hline System Design Element & Main Design Themes \\
\hline Digital Food-Taste Experience & Desired Food Experience \\
Suggestive & Food Suggestion List \\
Persuasive & Food Presentation \\
& Food Decision Making \\
Digital Taste Perception & Taste Perception \\
\hline
\end{tabular}

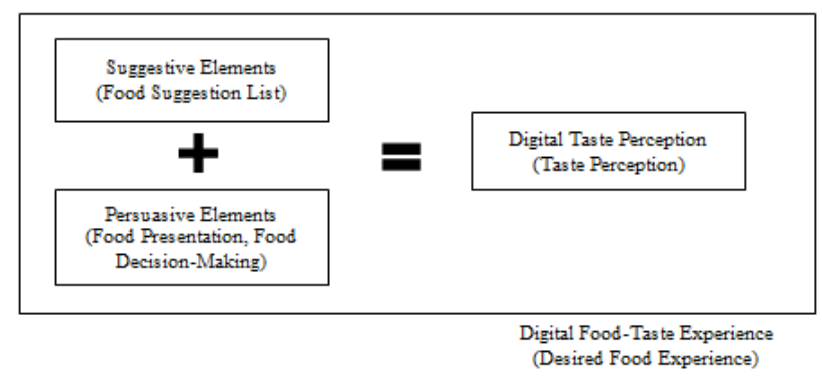

Figure 6. Digital Food-Taste Experience Design Model

\section{CONCLUSION}

Most of the tourists are curious with Malaysian local delicacies. Although most of them prefer exploring food for themselves, they would appreciate information such as pictures of food and ingredients to educate them on Malaysian dish to try out. However, it may be challenging when there is a need to rely on previous experience when making taste perception based on colours, texture and appearance. Due to our cultural differences and environmental upbringing, those elements may have different meaning affecting standardized perception among users towards Malaysian local dish.

The findings also imply that the key to digital food-taste perception is to show interaction with the food itself such as showcasing how ingredients come together and an actor demonstrating eating the food. Together, it could evoke user's eagerness of wanting to taste it. Nevertheless, the findings also indicate further gaps that needs addressing. This include, the use of actors from certain ethnicity to simulate eating experience so it is more relatable to them. The manner of which the local dish is presented also needs to be explored as it should generally be sanitary and clean yet represents street food identity rather than a regal 
magazine finishing. This is because tourist often try out local dish at the street market and an unrealistic image depiction can appear misleading affecting taste perception.

A further analysis on the findings were done resulting into a Digital Food-Taste Experience Design Model. It implies how in designing a digital platform for stimulating digital food-taste experience should consider components such as suggestive elements, persuasive elements and digital taste perception. However, the model's validity must be further investigated in terms of relationship validity and feasibility through system testing.

\section{ACKNOWLEDGEMENTS}

The authors would like to express the gratitude to the Ministry of Higher Education, Malaysia and Universiti Teknologi MARA, Shah Alam, Selangor for the financial support given for this project (FGRS Grant) [File No: 600-IRMI/FRGS 5/3 (0007/2016)]. Many thanks to Genovasi Malaysia for the Design Thinking experience and providing the facilities in enabling our study. We would also like to thank Mr Mohd Helme Mohd Helan from MESTECC for being our taste actor.

\section{REFERENCES}

[1] Henderson, J. C. (2009). "Food tourism reviewed". British Food Journal, 111(4), 317-326.

[2] Sims, R. (2009). "Food, place and authenticity: local food and the sustainable tourism experience". Journal of sustainable tourism, 17(3), 321-336.

[3] Yeoman, I., \& McMahon-Beatte, U. (2016). "The future of food tourism". Journal of Tourism Futures, 2(1), 95-98.

[4] Ellis, A., Park, E., Kim, S., \& Yeoman, I. (2018). "What is food tourism?”. Tourism Management, 68, 250-263.

[5] Frochot, I. (2003). "An analysis of regional positioning and its associated food images in French tourism regional brochures". Journal of Travel \& Tourism Marketing, 14(3-4), 77-96.

[6] Jalis, M. H., Che, D., \& Markwell, K. (2014). "Utilising local cuisine to market Malaysia as a tourist destination". Procedia-Social and Behavioral Sciences, 144, 102-110.

[7] Lertputtarak, S. (2012). "The relationship between destination image, food image, and revisiting Pattaya, Thailand". International Journal of Business and Management, 7(5), 111-121.

[8] Jalis, M. H., Che, D., \& Markwell, K. (2014). "Utilising local cuisine to market Malaysia as a tourist destination". Procedia-Social and Behavioral Sciences, 144, 102-110.

[9] Ab Karim, S., \& Chi, C. G. Q. (2010). "Culinary tourism as a destination attraction: An empirical examination of destinations' food image". Journal of hospitality marketing \& management, 19(6), 531-555.

[10] Tsai, C. T. S., \& Wang, Y. C. (2017). "Experiential value in branding food tourism". Journal of Destination Marketing \& Management, 6(1), 56-65.

[11] Zátori, A. (2013). "Tourism Experience creation from a business perspective". Budapest: Corvinus University NIVERSITY of Budapest.

[12] Hjalager, A. M., \& Corigliano, M. A. (2000). "Food for tourists-determinants of an image". International journal of tourism research, 2(4), 281-293.

[13] Murer, M., Aslan, I., \& Tscheligi, M. (2013, February). "LOLLio: exploring taste as playful modality". In Proceedings of the 7th International Conference on Tangible, Embedded and Embodied Interaction (pp. 299-302). ACM.

[14] Ranasinghe, N., Nakatsu, R., Hideaki, N., Gopalakrishnakone, P. (2012). "Tongue Mounted Interface for Digitally Actuating the Sense of Taste," in Proceedings of the 16th IEEE International Symposium on Wearable Computers (ISWC), pp. 80-87.

[15] Ranasinghe, N., \& Do, E. Y. L. (2017). "Digital lollipop: Studying electrical stimulation on the human tongue to simulate taste sensations". ACM Transactions on Multimedia Computing, Communications, and Applications (TOMM), 13(1), 5.

[16] Few, S. (2013). "Data visualization for human perception". The Encyclopedia of Human-Computer Interaction, 2nd Ed.

[17] Kahn, B. E., \& Deng, X. (2010). "Effects on visual weight perceptions of product image locations on packaging". Sensory marketing: Research on the sensuality of products, 259-278.

[18] Hong, S., Tandoc Jr, E., Kim, E. A., Kim, B., \& Wise, K. (2012). "The real you? The role of visual cues and comment congruence in perceptions of social attractiveness from Facebook profiles". Cyberpsychology, Behavior, and Social Networking, 15(7), 339-344.

[19] Deale, C. S. (2014). "Students' photo perceptions of hospitality and tourism in a community: A scholarship of teaching and learning case study". Journal of Teaching in Travel \& Tourism, 14(1), 1-21.

[20] Brown, T., \& Katz, B. (2011). "Change by design”. Journal of product innovation management, 28(3), 381-383.

[21] Dorst, K. (2011). "The core of 'design thinking' and its application”. Design studies, 32(6), 521-532.

[22] Kimbell, L. (2011). "Rethinking design thinking: Part I". Design and Culture, 3(3), 285-306.

[23] Kelley, D., \& Kelley, T. (2013). "Creative confidence: Unleashing the creative potential within us all". Crown Pub.

[24] Bannon, L. (2011). "Reimagining HCI: toward a more human-centered perspective". Interactions, 18(4), 50-57

[25] Hasso-Plattner-Institute (2018). "What is Design Thinking. Retrieved from https://hpi-academy.de/en/designthinking/what-is-design-thinking.html". 
[26] Brown, T., \& Wyatt, J. (2010). "Design thinking for social innovation”. Development Outreach, 12(1), 29-43.

[27] Kawenski, M. (1991). "Encouraging Creativity in Design". Journal of Creative Behavior, 25(3), 263-66.

[28] Kohn, N. W., \& Smith, S. M. (2011). "Collaborative fixation: Effects of others' ideas on brainstorming". Applied Cognitive Psychology, 25(3), 359-371.

[29] Scheer, A., Noweski, C., \& Meinel, C. (2012). "Transforming constructivist learning into action: Design thinking in education”. Design and Technology Education: An International Journal, 17(3).

[30] Genovasi (2018). "Post Programme Notes". Design Thinking Innovation Ambassador Program Kit.

[31] Bossert, S., Laessle, R. G., Meiller, C., Junker, M., Ellgring, H., \& Pirke, K. M. (2010). "Visual palatability of food in patients with eating disorders and dieting women". Universität Würzburg.

[32] Tuleu, C. (2011). "Acceptability and palatability-methods available for assessment". In Workshop on Paedriatric

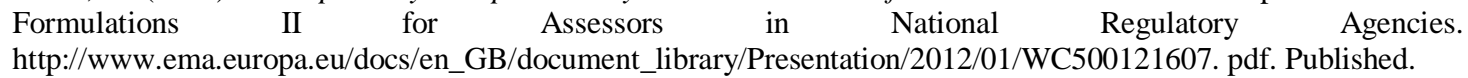

